\title{
钙钛矿量子点光伏与荧光聚光电池：现状与挑战
}

\author{
张枫娟 ${ }^{1,2}$, 韩博宁 ${ }^{2,3}$, 曾海波 ${ }^{2}$ \\ (1. 河南大学 特种功能材料重点实验室, 开封 475004; 2. 南京理工大学 材料科学与工程学院, 新型显示材料与 \\ 器件工信部重点实验室, 南京 210094; 3. 天津理工大学 材料科学与工程学院, 天津市光电显示材料与器件重点 \\ 实验室, 天津 300384)
}

摘 要: 太阳热辐射能储量丰富且无污染, 是未来最具竞争力的清洁能源之一。近年来, 卤化物钙钛矿量子点以其 优异的光电特性以及量子限域效应、可溶液加工等独特优势被广泛应用于太阳能电池和苂光型聚光太阳能电池，应 用前景广阔，但在未来的商业化应用中仍然面临诸多挑战。本文结合钻钛矿量子点太阳能电池领域的国内外研究进 展，重点归纳了提升电池性能的优化策略，并探讨了钻钛矿量子点在苂光聚光电池中的应用，最后阐述了该领域当 前面临的挑战，并对其发展趋势进行了展望，旨在为未来光伏技术的设计和开发提供一些思路，推进其研究进程。

关 键 词: 钻钛矿量子点; 太阳能电池; 苂光太阳能聚光器; 苂光型聚光太阳能电池; 综述

中图分类号: TQ174 文献标志码: A

\section{Perovskite Quantum Dot Photovoltaic and Luminescent Concentrator Cells: Current Status and Challenges}

\author{
ZHANG Fengjuan $^{1,2}$, HAN Boning ${ }^{2,3}$, ZENG Haibo ${ }^{2}$
}

(1. Key Laboratory for Special Functional Materials, Henan University, Kaifeng 475004, China; 2. MIIT Key Laboratory of Advanced Display Materials and Devices, School of Materials Science and Engineering, Nanjing University of Science and Technology, Nanjing 210094, China; 3. Tianjin Key Laboratory for Photoelectric Materials \& Devices, School of Materials Science and Engineering, Tianjin University of Technology, Tianjin 300384, China)

\begin{abstract}
Solar thermal radiant energy is abundant in storage and pollution-free, and is one of the most competitive clean energies in the future. In recent years, halide perovskite quantum dots (PQDs) are widely used in solar cells and luminescent concentrator solar cells due to their excellent photoelectric properties and unique advantages such as quantum confinement effect and solution processing, and possess vast application prospects, but they are still facing many challenges in future commercial applications. In this review, optimization strategies for improving cell performance are emphatically summarized based on the domestic and foreign research progress in the field of PQD solar cells. The application of PQDs in luminescent concentrator cells is introduced. Finally, the current challenges in this field are elaborated, and its development trends are prospected. This review provides some ideas for the design and development of the photovoltaic technology in the future.
\end{abstract}

Key words: perovskite quantum dot; solar cell; luminescent solar concentrator; luminescent concentrator solar cell; review

收稿日期：2021-07-13；收到修改稿日期：2021-09-14; 网络出版日期：2021-11-12

基金项目: 国家自然科学基金(61725402); 江苏省国际合作项目(BZ2020063); 中央高校基本科研专项资金(30919012107) National Natural Science Foundation of China (61725402); International Cooperation Program of Jiangsu Province (BZ2020063); Fundamental Research Funds for the Central Universities (30919012107)

作者简介：张枫娟(1991-), 女，博士. E-mail: fengj.zhang@henu.edu.cn

ZHANG Fengjuan (1991-), female, PhD. E-mail: fengj.zhang@henu.edu.cn

通信作者：曾海波，教授.E-mail: zeng.haibo@njust.edu.cn

ZENG Haibo, professor. E-mail: zeng.haibo@njust.edu.cn 
大力开发利用可再生清洁能源是解决能源短缺 问题的根本出路, 加快对太阳能的开发和利用也是 目前国内外的发展趋势。而卤化物钙钛矿因其优异 的光电特性(如高迁移率 ${ }^{[1-2]}$ 、长载流子扩散距离 ${ }^{[3-4]}$ 、 强光吸收能力 ${ }^{[5-6]}$ 等) 已经成为新一代最具竞争力的 光伏材料之一。截至目前, 单结钙钛矿太阳能电池 (SC) 的最高光电转换效率(PCE) 已达 $25.6 \%{ }^{[7]}$, 可与 商用的硅基 SC 相妶美, 而且钙钛矿材料合成工艺 简单、制造成本低廉，有望实现高效率、低成本的 商业化光伏技术。此外, 利用几何光学原理的聚光 技术与 $\mathrm{SC}$ 耦合形成聚光太阳能电池能够有效克服 太阳辐射的能流密度低的缺陷, 在进一步提高电能 输出的同时降低发电成本。荧光太阳能聚光器(LSC) 作为一种新兴的聚光技术, 相比于传统的聚光器 (反射镜、透镜等)具有独特的优势而受到关注, 在聚 光电池领域具有良好的发展前景。基于 LSC 组装的 聚光太阳能电池称之为荧光型聚光太阳能电池, 简 称荧光聚光电池。具有高荧光效率、宽吸收、窄发 射等优势的卤化物钙钛矿同样被广泛应用于 LSC 中 $^{[8-10]}$, 有望推动荧光聚光电池技术的发展。因此, 卤化物钙钛矿材料无论是作为光吸收材料还是作为 光转化材料在新一代光伏技术领域都具有巨大的应 用潜力。

目前, 基于单结钻钛矿多晶薄膜 SC 的 PCE 已 经突破 $25 \%{ }^{[7,11]}$, 为满足应用需求, 该类型 $\mathrm{SC}$ 的研 究主要集中在如何延长器件的使用寿命以及实现 无铅化。而钙针矿量子点(PQDs)太阳能电池因其带 隙可调、组分易控、电子状态好和表面态可调等优 点而备受关注, 与钲钛矿多晶薄膜 $\mathrm{SC}$ 相比, PQDs 还具有量子限域效应、溶液加工多样化等独特的优 势。但是其 PCE 相对较低 $\left(17.39 \%{ }^{[12]}\right.$, 最高认证效 率为 $16.6 \%{ }^{[13]}$ ), 仍然具有较大的提升空间。与此同 时, 虽然 PQDs 也是一种高效 LSC 的候选材料, 但 是其用于 LSC 的研究尚处于起步阶段, 基于该聚光 技术实现的聚光电池的外部光学效率仍然有待进一 步改善。

钙钛矿量子点面向光伏及苂光聚光电池的发展 仍然存在诸多挑战, 因此, 对该领域的研究现状进 行梳理, 能够为高性能光伏器件的设计和开发提供 参考, 同时本文最后明确指出该领域当前存在的各 项挑战和该领域未来的发展方向。

\section{1 钙钛矿量子点太阳能电池机理}

2009 年, 采用原位生长法制备得到的 $\mathrm{MAPbI}_{3}$ 和 $\mathrm{MAPbBr}_{3}$ ( $\mathrm{MA}$ 为甲基胺 $\mathrm{CH}_{3} \mathrm{NH}_{3}{ }^{+}$)量子点作为光
敏化剂被首次引入染料敏化 $\mathrm{SC}$ 中, PCE 达到了 $3.8 \%\left(\mathrm{MAPbI}_{3}\right)^{[14]}$ 。此后, 该结构类型 $\mathrm{SC}$ 的 $\mathrm{PCE}$ 进 一步提升至 $6.54 \%{ }^{[15]}$, 但是其采用的液态电解质会 腐蚀本就不太稳定的钙钛矿材料, 缩短电池寿命, 因此这种结构的钙钛矿 $\mathrm{SC}$ 并没有成为主流的研究 对象。直到 2012 年, 两项关于固态结构钙钛矿 SC 的研究被相继报道, 分别实现了 $9.7 \%{ }^{[16]}$ 和 $10.9 \%{ }^{[17]}$ 的 PCE, 开启了钲钛矿材料在 SC 领域的新篇章, 此 后, 相关的研究工作如雨后春笋般涌现。固态电池 结构也成了当前钻钛矿基 SC 的主流研究结构。

在钻钣矿量子点 $\mathrm{SC}$ 中, 最主要的两种固态器 件结构是介孔结构和平面异质结结构, 如图 1(a, b) 所示。介孔结构借鉴了染料敏化 SC 的构型，将液态 电解液更换为固态的空穴传输材料(HTM), 极大地 改善了电池稳定性 ${ }^{[16-17]}$ 。同时, PQDs 取代传统染料 作为吸光层负载在多孔 $\mathrm{TiO}_{2}$ 纳米颗粒多孔层骨架 上, 除了 $\mathrm{TiO}_{2}$, 其他介孔层骨架材料, 如 $\mathrm{ZnO}^{[18]}$ 、 $\mathrm{Al}_{2} \mathrm{O}_{3}{ }^{[19]} 、 \mathrm{ZrO}_{2}{ }^{[20]}$ 等也逐渐应用于光伏器件领域, 这 里介孔骨架的主要作用是传输电子, 还可以辅助钙 钛矿成膜。

平面异质结结构则摒弃了介孔骨架材料, 将 PQDs 直接置于 $\mathrm{p}$ 型和 $\mathrm{n}$ 型半导体之间，形成 “三明 治夹心” 结构, 利用钙钠矿材料自身载流子扩散长 度和寿命较长的优势来实现载流子的高效输运与收 集。平面结构根据量子点底层功能的不同还分为正 向(nip)和反向(pin)两种类型。在平面正向结构和上 述介孔结构中, $\mathrm{n}$ 型的 $\mathrm{TiO}_{2}$ 致密层为最常用的电子传 输材料 $(\mathrm{ETM})^{[21]}$, 用于收集电子的同时阻挡空穴。 在反向平面结构中, $p$ 型半导体 HTM 通常为聚 $(3,4-$ 乙烯二氧噻吩): 聚(苯乙烯磺酸盐)(PEDOT:PSS), n 型材料则主要是富勒烯及其衍生物 ${ }^{[22]}$ 。

以钙铁矿 $\mathrm{MAPbI}_{3}$ 吸光材料为例, 对钙钛矿量子 点 $\mathrm{SC}$ 的基本原理进行阐述，电池的能级示意图及 电子传输过程如图 1(c) 所示 ${ }^{[23]}$ 。 $\mathrm{MAPbI}_{3}$ 吸收入射光 后，处于基态的电子会从价带跃迁至导带，此时处 于激发态不稳定的电子和空穴在内建电场的作用下 发生分离; 激发态电子跃迁至 $\mathrm{TiO}_{2}$ 电子传输层的导 带(进程 1), 空穴跃迁至空穴传输层(spiro-OMeTAD, 即 2,2',7,7'-四 [ $N, N$-二(4-甲氧基苯基)氨基]-9, $9^{\prime}$-螺二 芴)的价带(进程 2), 进而分别被输运至负极和正极; 正负极之间形成电势差，在外接电路中形成光电 流。但是，电池在工作过程中常伴随出现某些负面 进程, 例如钙钛矿材料发生光致发光(PL)(进程 3)和 非辐射复合(进程 4)行为, 以及载流子在不同界面 处的复合行为(进程 5 7), 这些都会影响光生载流 子向正负极的有效输运, 从而降低电池的 $\mathrm{PCE}$ 。因 


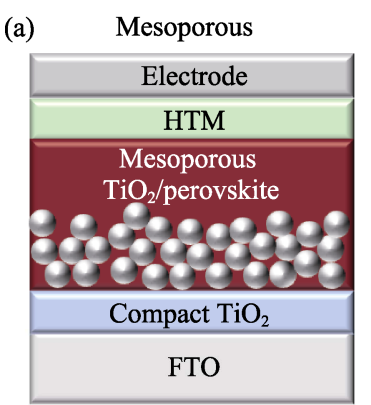

(b)

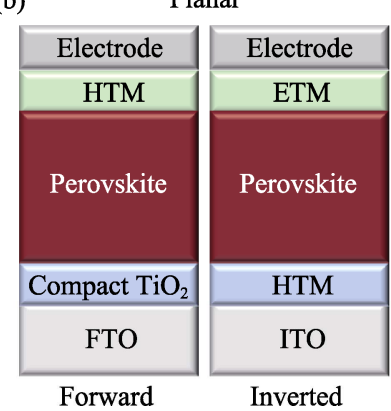

(c)

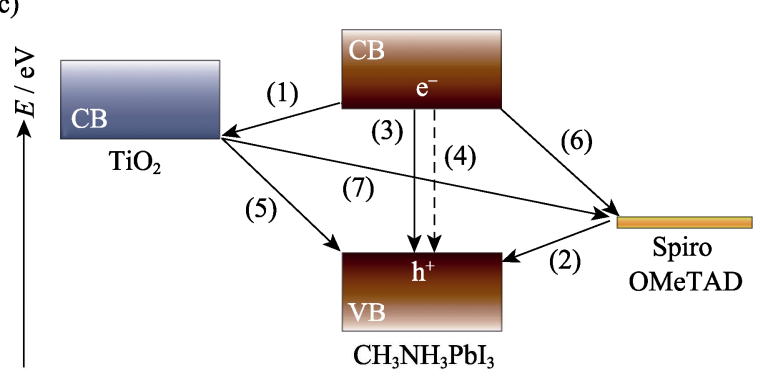

图 1 (a)介孔结构和(b)平面异质结结构的铛铁矿量子点太阳能电池示意图; (c)䥻钠矿太阳能电池的能级和电子传输过程示意图 ${ }^{[23]}$

Fig. 1 Schematic diagram of perovskite quantum dot solar cells with (a) mesoporous structure and (b) planar heterojunction structure, and (c) schematic diagram of energy levels and electron transfer processes of perovskite solar cells ${ }^{[23]}$

此，有效的光生载流子提取和载流子复合最小化是 实现高效 SC 的先决条件。

\section{2 太阳能电池性能优化策略}

为了获得高效钙钛矿量子点太阳能电池, 已经 开发了大量的性能优化策略。其中, PQDs 的组分调 控和表面改性从核心吸光材料出发, 界面优化从整 体器件考虑, 降低载流子在钙钛矿吸光层和界面处 的复合，达到提升电池性能的目的。本节将主要对 上述几种电池优化策略进行阐述与归纳。

\section{1 钙钛矿量子点组分调控}

胶体 PQDs 作为一种零维的纳米半导体吸光材料, 具有一定的结构柔韧性, 对钙钛矿晶体主要组成部分 进行离子取代或掺杂，会造成八面体的扭转 ${ }^{[24]}$, 从而 改变钙钛矿的物理特性。PQDs 的相结构 $\left(\mathrm{ABX}_{3}\right)$ 稳 定性可以根据 Goldschmidt 容忍因子 $t$ (公式(1))和八 面体因子 $\mu($ 公式(2))进行评估:

$$
\begin{gathered}
t=\frac{R_{\mathrm{A}}+R_{\mathrm{X}}}{\sqrt{2}\left(R_{\mathrm{B}}+R_{\mathrm{X}}\right)} \\
\mu=\frac{R_{\mathrm{B}}}{R_{\mathrm{X}}}
\end{gathered}
$$

其中, $R_{\mathrm{A}} 、 R_{\mathrm{B}} 、 R_{\mathrm{X}}$ 分别为 $\mathrm{A} 、 \mathrm{~B} 、 \mathrm{X}$ 的有效离子半 径 ${ }^{[25]}$ 。当 $t$ 和 $\mu$ 分别介于 $0.813 \sim 1.107$ 和 0.442 0.895 之间时, 获得的钙钛矿材料具备较好的晶体结构稳 定性，这也是对钙钛矿进行组分调控的基本准则。 PQDs 的组分调控主要分为 $\mathrm{A}$ 位、 $\mathrm{B}$ 位和 $\mathrm{X}$ 位的调 控, 如图 2(a)所示, B 位调控还分为部分掺杂或将 B 位的 $\mathrm{Pb}^{2+}$ 完全替换为无毒元素, 后者旨在获得无铅䥻 钛矿, 实现无铅化也是面向未来商业化发展的趋势。

A 位阳离子的主要作用是补偿钙钛矿晶格电荷, 维持晶格平衡。当 $t$ 和 $\mu$ 在上述范围内时, 增加(减 小) $R_{\mathrm{A}}$, 钙钛矿晶格发生膨胀(收缩), 从而影响 $\mathrm{B}-\mathrm{X}$ 离子键, 使带隙轻微变小(大), 进而造成光吸收带
边的红移(蓝移)。如图 2(b), 大尺寸甲㜆 $\mathrm{NH}_{2} \mathrm{CH}=$ $\mathrm{NH}_{2}{ }^{+}$(简称 FA) 的不断替换使得 $\mathrm{CsPbI}_{3}$ 量子点发生 PL 红移, 带隙变窄 ${ }^{[26]}$ 。但是 A 位掺杂过多或过少会 造成晶格严重畸变甚至发生相变, 例如 $\mathrm{Rb}^{+}$的尺寸 较小 $(t \approx 0.78)$, 难以形成稳定的晶体结构; 较大尺 寸的 $\mathrm{A}$ 位阳离子(如苯乙胺 ${ }^{[27]}$ 、丁胺 ${ }^{[28]}$ 等)会破坏钲 钛矿原始的三维结构, 形成低维度的钻钛矿材料。

对于 PQDs，常用的 A 位阳离子主要包括 MA、 $\mathrm{FA}$ 和 $\mathrm{Cs}^{+}$等。从容忍因子计算分析, $\mathrm{MA}$ 作为 $\mathrm{A}$ 位 阳离子能够实现理想的立方相 $\mathrm{PQDs}$, 但是 $\mathrm{MAPbI}_{3}$ 量子点在水、氧、光、热等环境下会发生分解与相变 (黑相到黄相), 不利于提升器件稳定性。使用挥发性 弱的 $\mathrm{FA}$ 和 $\mathrm{Cs}^{+}$完全替换 $\mathrm{MA}$ 的 $\mathrm{FAPbI}_{3}$ 和 $\mathrm{CsPbI}_{3}$ 量 子点可以改善 $\mathrm{SC}$ 的工作稳定性。且 $\mathrm{FAPbI}_{3}$ 能够进 一步拓宽吸收光谱(带隙约 $1.5 \mathrm{eV}$ ), 同时改善稳定 性, 但是其 PCE 相对较低 ${ }^{[26,29-30]}$ 。全无机 $\mathrm{CsPbI}_{3}$ 相 比有机-无机杂化钻钛矿则具有更高的热分解温度, 表现出更好的热稳定性, 但是 $\mathrm{Cs}^{+}$更小 $(t \approx 0.81)$, 不 利于维持晶格稳定 ${ }^{[31]}$, 同时带隙增大 $(1.73 \mathrm{eV})$, 不 利于可见光的吸收利用。而 $\mathrm{CsPbX}_{3}$ 量子点相比于 块体材料, 由于尺寸诱导的晶格应变以及表面能的 贡献增强，其晶格稳定性大大提高，这也是该类型 量子点材料可以稳定存在的原因 ${ }^{[32-33]}$ 。上述分析表 明纯 $\mathrm{A}$ 位阳离子制备得到的钙钣矿 $\mathrm{SC}$ 很难在保证 高效率的同时实现高稳定性。

混合 $\mathrm{A}$ 位阳离子掺杂策略可以综合不同阳离子 的自身优势，改善单一阳离子的劣势，提升太阳能 电池性能。例如, MA 和 FA 有机阳离子混合不但能 够提高短路电流, 而且可以提升器件效率, 改善稳 定性 ${ }^{[34-35]}$ 。此外, 作为 $\mathrm{Cs} / \mathrm{FA}$ 混合阳离子体系 ${ }^{[12-13,26]}$, 基于 $\mathrm{Cs}_{0.5} \mathrm{FA}_{0.5} \mathrm{PbI}_{3}$ 量子点 $\mathrm{SC}$ 的 $\mathrm{PCE}$ 高达 $16.6 \%{ }^{[13]}$, 为目前基于 $\mathrm{PQDs}$ 太阳能电池的最高认证效率，在 连续标准太阳光照射下，可保持 $94 \%$ 的原始 PCE 约 $600 \mathrm{~h}$, 稳定性获得极大提升。综上所述, PQDs 晶格 


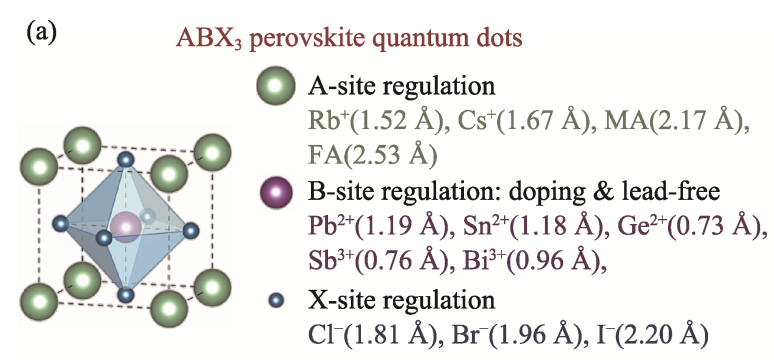

(c)

Defect intolerant, Defect tolerant,
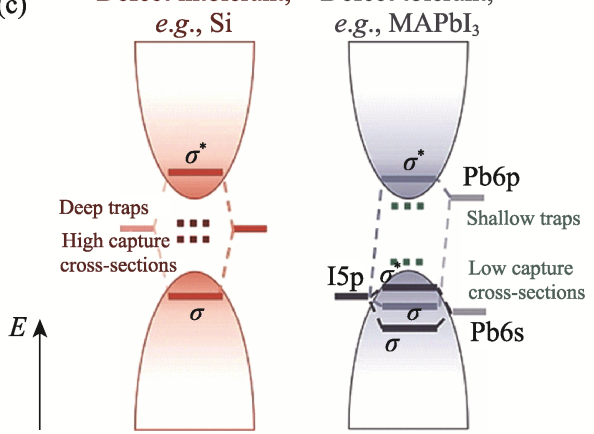

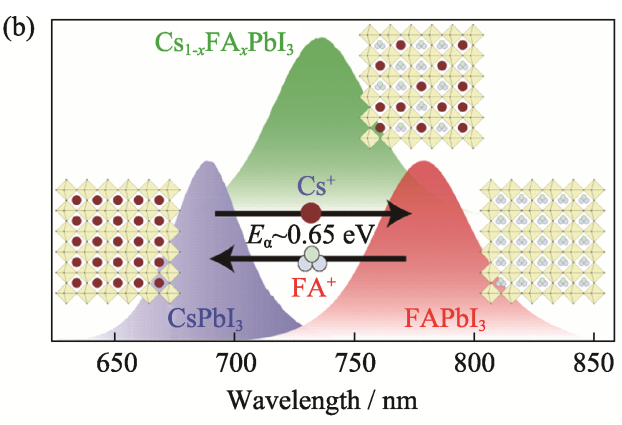

(d) $\frac{\text { Partial B-site cation substitution of } \mathrm{CsPbX}_{3}}{\mathrm{CsPbI}_{3}}$

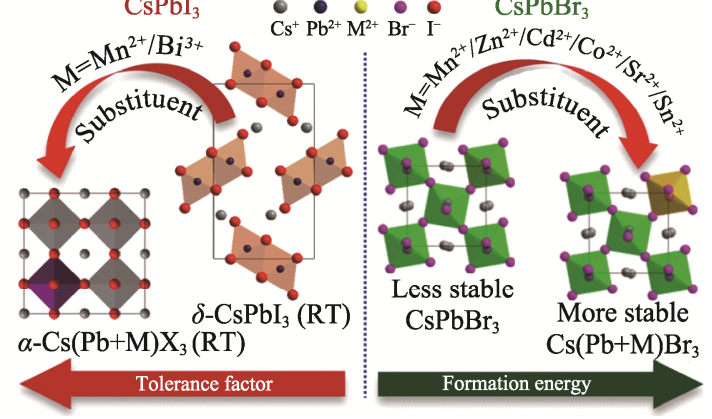

图 2 (a) PQDs 的晶体结构示意图及组分调控 $\left(1 \AA=0.1 \mathrm{~nm}\right.$ ); (b) PQDs 的 $\mathrm{A}$ 位阳离子交换示意图及相应的 PL 光谱 ${ }^{[26]}$; (c) 典型 缺陷不容半导体和缺陷可容钻铁矿的电子能带结构图 ${ }^{[36]}$; (d) 不同金属离子部分替换 $\mathrm{B}$ 位 $\mathrm{Pb}^{2+}$ 以改善稳定性的原理示意图 ${ }^{[4]}$

Fig. 2 (a) Crystal structure diagram and composition regulation of PQDs ( $1 \AA=0.1 \mathrm{~nm}$ ); (b) Illustration of the A site cation exchange process and the corresponding photoluminescence (PL) spectra of PQDs ${ }^{[26]}$; (c) Illustration of the electronic band structure of typical defect intolerant semiconductors and defect tolerant perovskites ${ }^{[36]}$; (d) Schematic of $\mathrm{Pb}^{2+}$ at B site partially substituted by various metal ions to improve stability ${ }^{[41]}$

的 $\mathrm{A}$ 位组分调控有助于稳定相结构, 是提高电池性 能的有效策略之一。

$\mathrm{B}$ 位阳离子对钙铁矿的电子性质和晶体结构有 重要影响。 $\mathrm{Pb}^{2+}$ 是最典型的 $\mathrm{B}$ 位阳离子, 其与 $\mathrm{X}$ 位 卤素形成的 $\left[\mathrm{PbX}_{6}\right]^{4-}$ 八面体构成了钙钛矿结构的基 本框架, 式(1)和式(2)显示 $\mathrm{B}$ 位阳离子对钙钣矿晶体 稳定性至关重要。图 2(c)中传统 $\mathrm{Si}$ 基半导体的带隙 在成键轨道 $(\sigma)$ 和反键轨道 $\left(\sigma^{*}\right)$ 之间形成, 点缺陷或 悬空键以弱键合或非键合状态出现在带隙内, 主要 为深能级缺陷 ${ }^{[36-37]}$ 。而钙钛矿的带隙在两个 $\sigma^{*}$ 之间 形成, 缺陷态仅仅在浅能级中形成, 或被封闭在导 带或价带内, 这说明钙针矿的电学性能对材料和表 面的缺陷具有很高的容忍度, 这也是钙钛矿材料在 光电子器件领域的一大优势。另外, 钙钛矿的导带 底与 $\mathrm{Pb}$ 的 $6 \mathrm{p}$ 轨道有关, 价带顶与卤素的 $5 \mathrm{p}$ 轨道和 $\mathrm{Pb}$ 的 $6 \mathrm{~s}$ 轨道有关, 因此, 改变卤素对价带影响更大, 而 $\mathrm{Pb}$ 的 $6 p$ 轨道对导带影响提供主要贡献 ${ }^{[38-39]}$ 。

针对最典型的 $\mathrm{B}$ 位 $\mathrm{Pb}$ 元素的毒性问题, 急需无 毒或低毒的替代元素, 这也是未来商业化发展的关 键。由于反应活化能高, 对 PQDs 中的 B 位进行掺 杂或合金化要难于 $\mathrm{A}$ 位和 $\mathrm{X}$ 位 ${ }^{[40]}$, 因此很难采用离 子交换的方式实现。 $\mathrm{CsPbX}_{3}$ 量子点是该组分调控策 略最普遍的研究对象, 从容忍因子 $t$ 计算公式分析,
要实现更加稳定的相结构, 需要采用离子半径比 $\mathrm{Pb}^{2+}$ 更小的阳离子进行掺杂或取代, 这会导致晶格 收缩, 结合能增大。常用的替换阳离子包含同价的 $\mathrm{Sn}^{2+} 、 \mathrm{Ge}^{2+} 、 \mathrm{Zn}^{2+}$ 和 $\mathrm{Mn}^{2+}$, 还有异价的 $\mathrm{Ag}^{+} 、 \mathrm{Sb}^{3+}$ 和 $\mathrm{Bi}^{3+}$ 等。图 2(d)展示了不同金属离子部分替换 $\mathrm{Pb}^{2+}$ 以改善 $\mathrm{CsPbBr}_{3}$ 和 $\mathrm{CsPbI}_{3}$ 稳定性的原理示意图, B 位 掺杂既能够增大钙钛矿的容忍因子, 还能够提高形 成能, 从而增强钲钛矿晶体结构的稳定性 ${ }^{[41]}$ 。此外, B 位掺杂还能够针化钙铁矿的缺陷, 抑制非辐射复 合, 进而改善 PCE。事实上, 虽然 B 位掺杂剂进入 钙铁矿晶格的实际比例很低, 但是其仍会对钙钛矿 的结构和性能产生极大影响。

无铅化 PQDs 也是 SC 领域的研究热点, 同主族 的 $\mathrm{Sn}$ 和 $\mathrm{Ge}$, 与 $\mathrm{Pb}$ 有相似的电子结构, $\mathrm{Sn}$ 基 PQDs 的研究最为广泛, 是最有前途的铅卤钻钛矿取代体 系之一。但是 $\mathrm{Sn}^{2+}$ 极易被氧化成 $\mathrm{Sn}^{4+}$, 引起内部自 掺杂效应，破坏原有的晶体结构。亚磷酸三苯酯作 为抗氧化剂可以抑制 $\mathrm{Sn}^{2+}$ 的氧化, 使得 $\mathrm{CsSnI}_{3}$ 量 子点 $\mathrm{SC}$ 的 $\mathrm{PCE}$ 达到 $5.03 \%$, 器件的长期稳定性也 得到了改善 ${ }^{[42]}$ 。 $\mathrm{Sn} / \mathrm{Ge}$ 合金化的 $\mathrm{CsSn}_{0.6} \mathrm{Ge}_{0.4} \mathrm{I}_{3}$ 能够 钝化 $\mathrm{Sn}$ 空位, 减少表面缺陷, 改善 $\mathrm{SC}$ 的效率和稳 定性 ${ }^{[43]}$ 。

除了等价离子，通过理论计算表明，采用异价金 
属阳离子 $\left(\mathrm{Na}^{+}, \mathrm{Ag}^{+}, \mathrm{Bi}^{3+}, \mathrm{Sb}^{3+}, \mathrm{In}^{3+}\right)$ 的双钙铁矿结构 也是实现无铅化电池的可行方法。其中 $\mathrm{Cs}_{2} \mathrm{AgBiBr}_{6}$ 量子点已经成功应用于平面异质结结构的光伏器 件 ${ }^{[44]}$, 虽然器件的 PCE 较低 $(0.46 \%)$, 但是双钙钛矿 量子点在光伏应用中的可行性得到了验证。

$\mathrm{X}$ 位阴离子 $\left(\mathrm{Cl}^{-}, \mathrm{Br}^{-}, \mathrm{I}^{-}\right)$对钙钛矿的价带起主导 作用, 通过改变卤素离子的种类和配比, 可以大幅 度调节 PQDs 的光学带隙。由于 PQDs 具有离子晶 体特性、高度动态表面及低的卤素迁移势垒, 因而 $\mathrm{X}$ 位组分调控极易操作, 在合成前、中、后任意进 程中引入不同类型的卤素离子均可实现。为了提高 钻铁矿对长波区域的光吸收, $I^{-}$是最常用的 $X$ 位阴 离子, 但是 I 基钻钛矿在室温条件下很容易相变成 宽带隙的 $\delta$ 相, 相稳定性欠佳。除了混合 $\mathrm{A}$ 位阳离子, 电负性更强的 $\mathrm{Br}^{-}$取代也能够提高 PQDs 的分解能, 从而改善其稳定性 ${ }^{[45]}$ 。但是引入小尺寸卤素离子会 增加带隙, 减少长波长处的光吸收, 因此需要仔细 调节掺杂比例, 在稳定性和光伏效率之间寻求平衡。

\section{2 钙钛矿量子点表面改性}

PQDs 表面附着的有机配体(油酸或油胺)是获 得良好分散性和稳定性的关键, 同时能够钝化缺陷 从而实现高荧光效率, 但是这些长链的绝缘配体会 阻碍光生载流子的传输。此外, 配体在 PQDs 表面 的吸附是一个动态过程, 极易在纯化及成膜的过程 中丢失, 从而导致过多的表面缺陷, 阻碍电荷的收 集与传输, 甚至造成 PQDs 在高极性溶剂中的不利 相变。因此, PQDs 的表面改性对于实现高效稳定的 $\mathrm{SC}$ 至关重要。

表面配体的种类、链长及密度都会影响 PQDs 的光电特性及稳定性。以 $\alpha-\mathrm{CsPbI}_{3}$ 量子点为例, 如 图 3(a)所示, 理论计算显示该量子点表面的短链配 体辛酸和辛胺 $(\mathrm{C} 8)$ 的吸附能大于长链的油酸和油胺 (C18), 因此, C18 体系配体极易丢失, 形成大量新 的表面缺陷甚至相变为非钙钛矿相(图 3(b)), 而 C8/ C18 混合体系配体与 PQDs 之间具有更强的结合作 用，稳定性得到极大提升，同时短链配体还能够促进 电荷传输, 使电池的 PCE 从 $7.76 \%$ 提升至 $11.87 \%$ 。

除了在合成过程中引入不同种类的表面配体, 还可以在合成后利用溶液配体交换来补充短链配体 或通过控制配体密度等表面改性方法来提高 PQDs 的光伏性能。例如, 短链的硫氰根 $\left(\mathrm{SCN}^{-}\right)^{[47]}$ 和苯基 三甲基溴化铵 $(\mathrm{PTABr})^{[48]}$ 被用来与 $\mathrm{CsPbI}_{3}$ 量子点的 长链配体进行溶液配体交换, 不但能够缩短成膜后 量子点之间的距离, 改善载流子传输, 而且可以钝 化卤素空位缺陷, 改善电池性能。前者结合 $\mathrm{Mn}$ 掺 杂、FA 表面修饰以及组分梯度异质结等策略最终使
PCE 达到 $14.45 \%$ 。此外, 利用正己烷/乙酸甲酯 (MeOAc)溶剂处理方法控制 $\mathrm{CsPbBr}_{2} \mathrm{I}$ PQDs 的表面 配体数量, 使得 PQDs 薄膜的质量、电荷转移和输运 性能得到极大改善。进一步对薄膜退火 $\left(330{ }^{\circ} \mathrm{C}\right)$ 诱导 部分晶体熔合来改善界面，使得 PCE 从 $5.9 \%$ 提高到 $12.2 \%{ }^{[49]}$ 。该方法也同样被应用于发光显示领域，证 明了该策略的通用性 ${ }^{[50-51]}$ 。

胶体 PQDs 从溶液态沉积为厚的固态吸收薄 膜常需采用层层旋涂的方法制备, 流程示意图如 图 3(c)所示, $\mathrm{PQDs}$ 旋涂成膜后常浸于 $\mathrm{Pb}\left(\mathrm{NO}_{3}\right)_{2}$ 或 $\mathrm{Pb}(\mathrm{OAc})_{2}$ 的 $\mathrm{MeOAc}$ 饱和溶液中, 再使用 $\mathrm{MeOAc}$ 反 溶剂冲洗, 重复 3 5 次该过程, 即得到一定厚度的 PQDs 吸光层 ${ }^{[12]}$ 。而具有双重针化功能的短链甘氨 酸配体也可以替换上述的 $\mathrm{Pb}\left(\mathrm{NO}_{3}\right)_{2}$ 来修饰表面、针 化缺陷，将 PCE 从 $11.69 \%$ 提升至 $13.66 \%{ }^{[52]}$ 。

在上述 PQDs 固态薄膜的浸泡和冲洗过程中, 如图 3(d)所示, 如果有外源水分子存在, 则水分子 与 $\mathrm{MeOAc}$ 发生水解反应, 生成醋酸根, 并部分取代 油酸发生阴离子交换 ${ }^{[53]}$, 因此, 醋酸根可作为常用 的阴离子交换源 ${ }^{[54]}$ 。而形成厚吸光层后，引入一些 短链配体 (如 MAI 和 FAI) 可以与油胺发生阳离子交 换。这种短链配体交换会缩短量子点之间的间距, 从而增强钙铁矿之间的电耦合，促进光生载流子的 萃取和输运, 达到提升 PCE 的目的。Sanehira 等 ${ }^{[55]}$ 也利用不同的 $\mathrm{AX}$ 盐 $\left(\mathrm{A}=\mathrm{FA}, \mathrm{MA}\right.$ 和 $\mathrm{Cs}^{+}, \mathrm{X}^{-} \mathrm{Br}^{-}$和 $\left.\mathrm{I}^{-}\right)$ 进行表面处理(图 3(e)), 改善了器件在吸光层的电 荷输运, PCE 获得了不同程度的提升 (最高达 $13.43 \%)$ 。除此之外, 不同链长的苯铵碘(PAI)、苄基 铵碘(BAI)和苯乙胺碘(PEAI), 不同的 Cs 盐(如 CsAc, $\left.\mathrm{Cs}_{2} \mathrm{CO}_{3}, \mathrm{CsNO}_{3}\right)$ 也是 $\mathrm{AX}$ 处理盐的备选 ${ }^{[54,56]}$ 。通过硫 氰酸胍(GASCN)配体交换处理, 再辅助温和退火也 可以增强 $\mathrm{CsPbI}_{3}$ 钙钛矿间的电耦合(图 3(f)), $\mathrm{PCE}$ 高 达 $15.21 \%$, 这里 $\mathrm{GA}$ 起主导作用。该策略在 $\mathrm{CsPbBr}_{3}$ 和 $\mathrm{FAPbI}_{3}$ 量子点体系均有效, 具有通用性 ${ }^{[57]}$ 。

综上所述, PQDs 溶液态和固态的表面改性主 要针对长链的油酸和油胺配体的绝缘特性不利于载 流子输运的问题, 期望采用传输特性好的短链配体 进行封端, 从而为提高器件光伏性能提供一条重要 途径。

\section{3 器件界面工程}

诺贝尔物理学奖获得者 Herbert Kroemer 曾说 过“界面就是器件”, 说明了界面在器件中的关键作 用。SC 中有效的电荷提取除了要保证好的 PQDs 吸 光材料, 还需要更加匹配的能级结构、良好的界面 接触。因此, 本节聚焦器件界面工程进行阐述。 
(a)

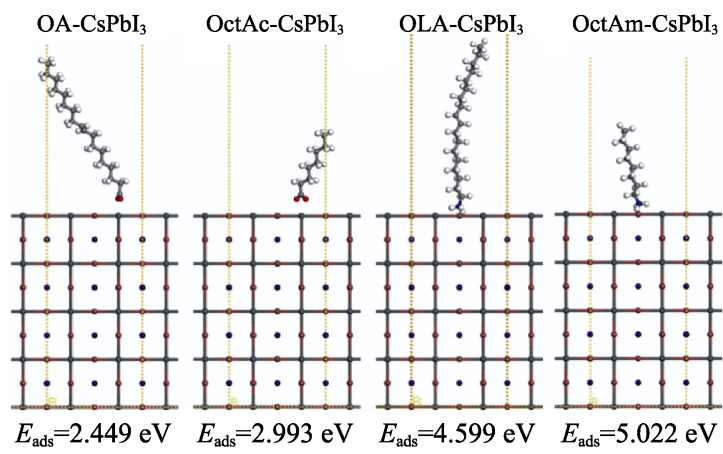

(b)

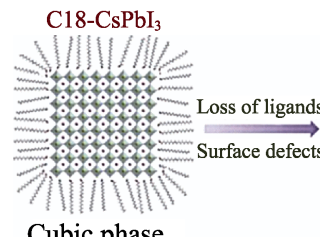

Cubic phase

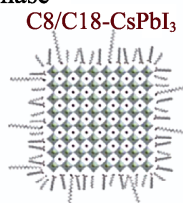

Cubic phase

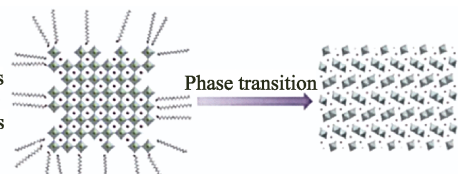

Orthorhombic phase (c)

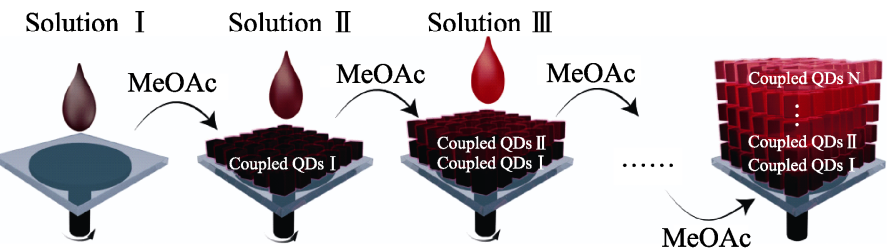

(e)

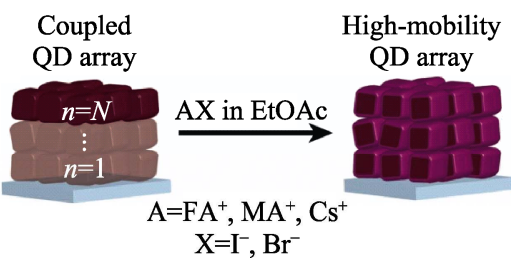

(f)

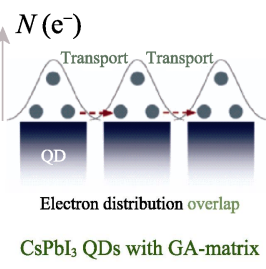

(d)

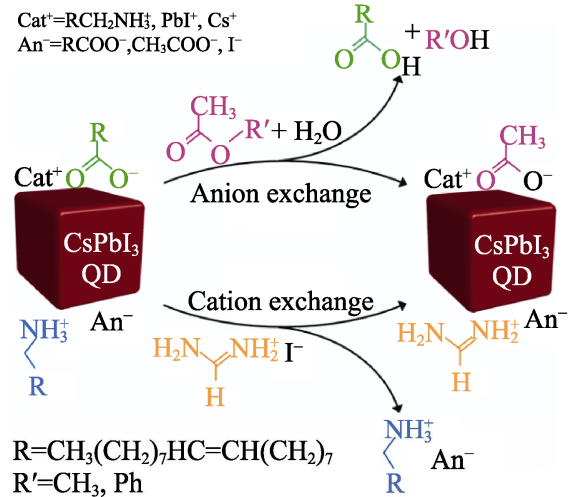

图 3 (a)不同链长配体吸附在 $\alpha-\mathrm{CsPbI}_{3}$ 量子点表面的理论模型及吸附能; (b) $\mathrm{CsPb} \mathrm{I}_{3} \mathrm{QDs}$ 在 $\mathrm{C} 8$ 和 $\mathrm{C} 8 / \mathrm{C} 18$ 配体体系中的 稳定机制示意图 ${ }^{[46]}$; (c)PQDs 的层层组装示意图 ${ }^{[12]}$; (d)PQDs 薄膜的阴阳离子配体交换反应示意图 ${ }^{[33]}$; (e)PQDs 薄膜的 $\mathrm{AX}$ 盐后处理过程 ${ }^{[55]}$; (f) GA 封端的 PQDs 间由于点间距减小而电耦合增强的示意图 ${ }^{[57]}$

Fig. 3 (a) Theoretical model and adsorption energy for various ligands with different chain length adsorbed on the surface of $\alpha-\mathrm{CsPbI}_{3}$ QDs; (b) Schematic of the stabilization mechanism of $\mathrm{CsPbI}_{3}$ QDs in $\mathrm{C} 8$ and $\mathrm{C} 8 / \mathrm{C} 18$ ligand systems ${ }^{[46]}$;

(c) Schematic of layer-by-layer assembly of $\mathrm{PQDs}^{[12]}$; (d) Schematic of anion and cation ligand exchange reaction of

PQD films ${ }^{[53]}$; (e) AX salt post-treatment process of the PQD films ${ }^{[55]}$; (f) Illustration of enhanced electrical coupling between the GA-capped PQDs as a result of reduced interdot distance ${ }^{[57]}$

PQDs 吸光层形成异质结可以辅助电荷在界面

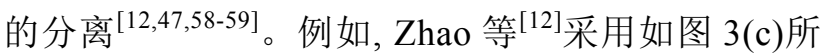
示的层层组装方法, 将不同组分的 $\mathrm{Cs}_{1-x} \mathrm{FA}_{x} \mathrm{PbI}_{3}$ 与 $\mathrm{CsPbI}_{3}$ 量子点逐层沉积, 即可形成异质结结构的有 源层, 图 4(a) 为 $\mathrm{Cs}_{1-x} \mathrm{FA}_{x} \mathrm{PbI}_{3}$ 量子点及其接触层的 能带结构, 不同能带位置带来的内部异质结可以 促进电荷在有源层界面处的分离, 从而改善光生载 流子捕获。同时, 引入 $\mathrm{FA}$ 也扩展了光吸收范围, 最 终 $\mathrm{Cs}_{0.25} \mathrm{FA}_{0.75} \mathrm{PbI}_{3} / \mathrm{CsPbI}_{3}$ (厚度比为 $1: 3$ ) 的异质结 器件的 PCE 达到了 $17.39 \%$, 为目前报道的最高记 录。因此，构建这种异质结构吸光层是一种极为有 效的提高光伏性能的策略。

前述已经提到层层组装 PQDs 吸收层, 需要浸泡 和冲洗流程, 这其实可以认为是界面的处理过程, 在 去除部分长链配体的同时辅助制备后续高质量 PQDs 层。除了 PQDs 吸光层自身形成异质结之外, 杨阳 团队 ${ }^{[60]}$ 在乙酸乙酯反溶剂中引入共轭小分子(ITIC), 与量子点之间形成异质结构, ITIC 分子可以提供额 外的电荷分离驱动力, 进而抑制载流子的复合, 其
原理图解如图 4(b), 最终基于 $\mathrm{FAPbI}_{3}$ 量子点的光 伏器件的 PCE 达到 $12.7 \%$ 。受此启发, 其他的电荷 提取分子如 2,3,5,6-四氟-7, $7^{\prime}, 8,8^{\prime}$-四氰二甲基对苯 醌(F4-TCNQ $)^{[61]}$ 也是选择之一。此外, PQDs 还可以 与其他类型的量子点如 $\mathrm{PbSe}^{[62]}$, 金属氧化物如 $\mathrm{TiO}_{2}, \mathrm{NiO}_{x}{ }^{[63]}$ 形成异质结构，在促进电荷分离的同 时大幅改善器件的稳定性。

PQDs 表面具有的绝缘特性长链有机配体除了 采用配体交换之外，还可以从引入高导电性的材料 入手, 如微米尺寸的石墨烯 ( $\mu$-石墨烯), 层状结构 可以充当电子传输通道, 还可以作为防潮/热屏障, 抑制外部环境诱导 PQDs 团聚引起的不稳定性，相关 的机理解析如图 4(c)所示, 更快的电荷提取使得器 件 PCE 从 $10.17 \%$ 提升至 $11.40 \%$, 更重要的是在 $60 \%$ 的湿度和 $100{ }^{\circ} \mathrm{C}$, , 器件的工作寿命更长 ${ }^{[64]}$ 。这里 $\mu$ 石墨烯作为界面传输材料, 为解决绝缘配体电荷输 运能力差的问题提供了思路。

光伏器件的其他功能层的界面问题也不容忽 视。 $\mathrm{TiO}_{2}$ 与 $\mathrm{PQDs}$ 能带结构较为匹配, 是 $\mathrm{SC}$ 领域应 
(a)

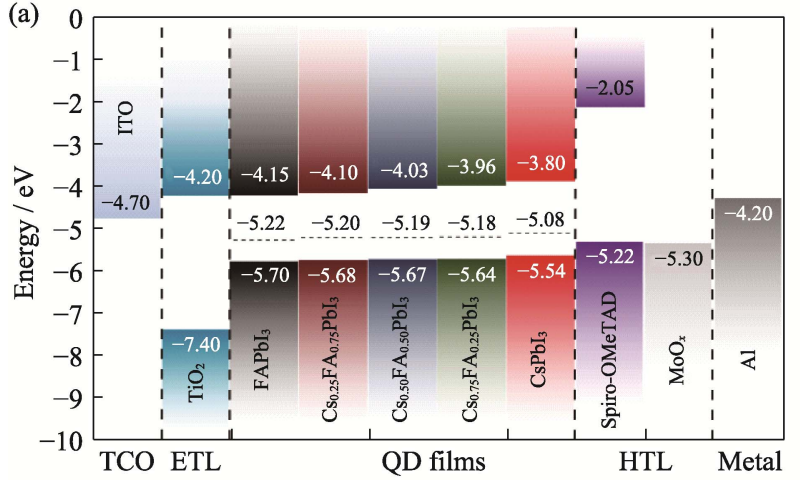

(c)

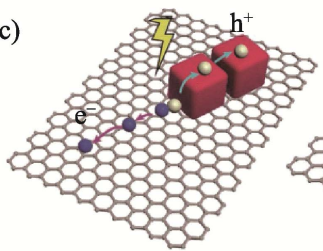

Charge transport channel

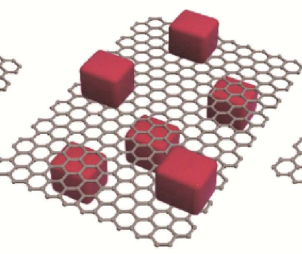

Agglomeration spacer

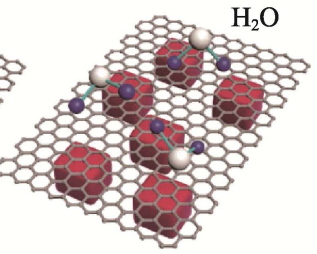

Moisture barrier

(d)
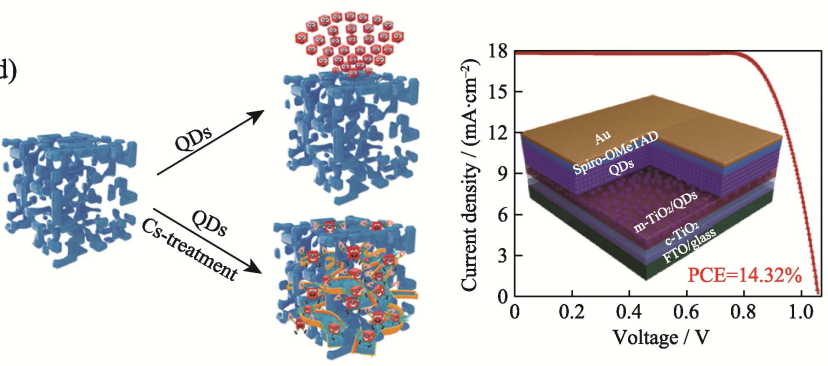

(b)

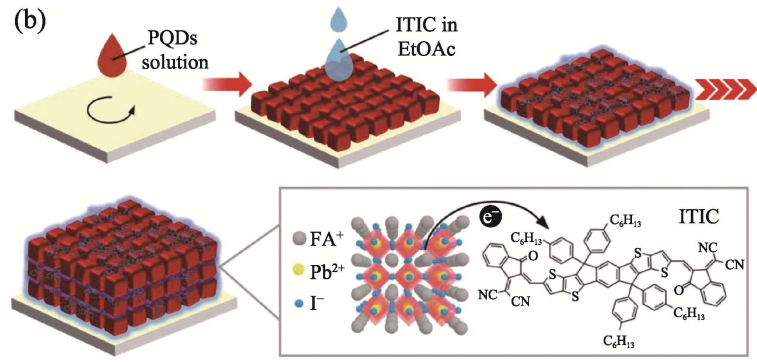

(e)

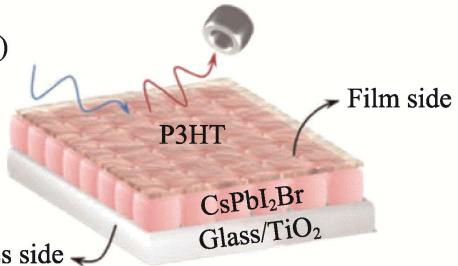

(1)

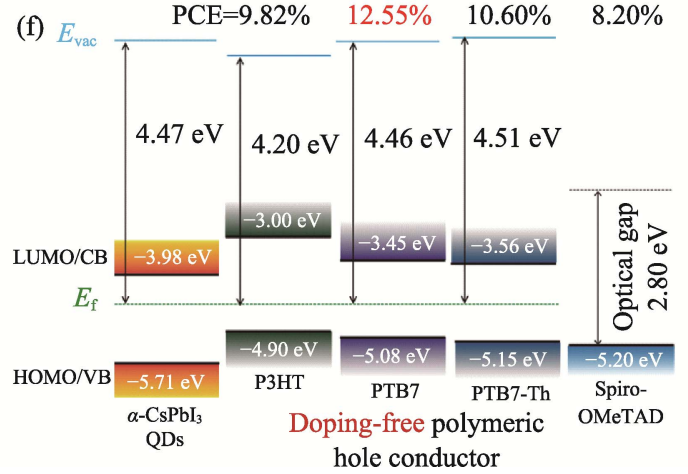

图 4 (a)基于不同组分 PQDs 的 SC 能带结构, 水平虚线表示费米能级位置 ${ }^{[12]}$; (b) $\mathrm{FAPbI}_{3} \mathrm{QD} / \mathrm{ITIC}$ 薄膜制备原理图 ${ }^{[60] ;}$ (c) $\mu$-石墨烯交联 PQDs 太阳能电池的电荷输运过程及稳定机制示意图 ${ }^{[64]}$; (d)介孔 $\mathrm{TiO}_{2}$ 的 $\mathrm{Cs}$ 处理示意图, 以及相应具有 介孔结构 SC 的示意图和电流密度-电压曲线 ${ }^{[65]}$; (e)P3HT 修饰的 PQD 薄膜 ${ }^{[71]}$; (f) 具有不同聚合物 HTM SC 的能带结构 ${ }^{[72]}$

Fig. 4 (a) Energy band structures for SC based on PQDs with different compositions ${ }^{[12]}$ with horizontal dotted line indicating the Fermi level positions; (b) Schematic of FAPbI 3 QD/ITIC film fabrication ${ }^{[60]}$; (c) Schematic of the charge transport process and stabilization mechanism for SC based on $\mu$-graphene crosslinked PQDs ${ }^{[64]}$; (d) Schematic of Cs-treatment on mesoporous $\mathrm{TiO}_{2}$, and schematic view and $J-V$ curve of corresponding $\mathrm{SC}$ with mesoporous structure ${ }^{[65]}$; (e) P3HT modified PQD film ${ }^{[71]}$; (f) Energy band structures of SC with different polymeric HTM $^{[72]}$

用最广泛的 ETM 之一。在体相铛铁矿 SC 中, 介孔 $\mathrm{TiO}_{2}$ 与钙铁矿之间大的接触面积有助于提取电子, 但是 PQDs 却难以进入多孔骨架的孔隙, 阻碍了介 孔结构在 PQDs SC 的应用。为了尝试解决该问题, Chen 等 ${ }^{[65]}$ 使用富电子的醋酸铯 $\mathrm{MeOAc}$ 溶液处理介 孔 $\mathrm{TiO}_{2}$ 骨架层(图 4(d)), 降低了 $\mathrm{TiO}_{2}$ 表面的固液界 面张力, 提高了润湿性, 促进量子点进入孔隙。同时 $\mathrm{Cs}^{+}$还可以针化量子点表面, 促进界面电荷转移, 最 佳 PCE 达到 14.32\%。

虽然介孔 $\mathrm{TiO}_{2}$ 具有促进电子提取的优点, 但是 光滑平坦的致密 $\mathrm{TiO}_{2}$ 层更有利于 $\mathrm{PQDs}$ 吸光层的旋 涂沉积, 因此平面结构在 PQDs SC 中应用更为广 泛。目前, $\mathrm{TiO}_{2}$ 电子传输层还存在高温腶烧、电子 迁移率不高、紫外光照射不稳定等缺陷, 限制了其 在新一代柔性器件中的应用。而可低温制备的纳米 结构 $\mathrm{SnO}_{2}$ 具有能级匹配、电子迁移率高、光稳定性
好以及透光率佳等优点, 成为 ETM 的候选 ${ }^{[6-67] 。}$ 。例 如, Jia 等 ${ }^{[52]}$ 采用低温溶液法制备的 $\mathrm{SnO}_{2}$ 层作为电 子传输层, PCE 达到 $13.66 \%$ 。其中便于层层旋涂组 装的平面结构很容易实现, 可低温处理的特性也使 $\mathrm{SnO}_{2}$ 具备了成为柔性器件 ETM 的潜力。但是电子 传输层与 $\mathrm{PQDs}$ 吸光层的界面接触面积较小, 因此 需要进一步研究通过界面工程来促进该界面上的电 荷转移。比如引入 $\mathrm{Cl}$ 离子可以针化 $\mathrm{SnO}_{2}$ 的表面缺 陷, 抑制界面缺陷捕获电子, 同时使其导带位置上 移, 促进电荷的提取, 将 PCE 提高到 $14.5 \%{ }^{[68]}$ 。

倒置 pin 结构中的 ETM 也需要在低温下制备, 以免破坏下层 PQDs 吸光层。除了富勒烯及其衍生 物之外, $\mathrm{NiO}_{x}$ 也是 $\mathrm{ETM}$ 的备选 ${ }^{[69]}$ 。与传统正置 nip 结构相比, 倒置器件的效率仍然很低, 可能是光生 载流子在界面复合所致, 因此开发更合适的 ETM 以及合理的界面处理方法仍是改善电池性能的有效 
策略。

为了有效提取空穴, HTM 需要具备合适的能级 和高空穴迁移率, 同时还起到阻挡电子并防止 PQDs 吸光层降解的作用。在钙钛矿 $\mathrm{SC}$ 中, 有机小 分子 Spiro-OMeTAD 是最常用的 HTM, 但是其空穴 传输能力较差, 常需通过一些吸水性的 $\mathrm{P}$ 型有机添 加剂进行改善, 如锂盐(LiTFSI)和叔丁基吡啶等 ${ }^{[70]}$, 却也严重影响了钙铁矿材料和器件的稳定性。另 外, 由于 Spiro-OMeTAD 制备工艺复杂, 纯度要 求高, 价格昂贵, 无法满足商业过程的大规模应 用。因此, 迫切需要找到价格低廉、稳定性好且 工艺简单的 HTM。

具有强电荷提取能力的共轭聚合物可以作为 HTM 替换 Spiro-OMeTAD, 达到修饰 PQDs/HTM 界 面的目的 ${ }^{[71-72]}$ 。如图 4(e,f), 这些共轭聚合物除了在 能级上与 PQDs 更匹配, 有利于电荷分离之外, 与 PQDs 之间有强的相互作用和良好的物理接触, 能 够针化缺陷、抑制载流子的复合, 而本身的强电荷 提取能力进一步促进了钙钛矿中的电荷提取, 均可 以不同程度改善电池性能。无机 $\mathrm{HTM}$, 如 $\mathrm{CuSCN}^{[73]}$ 和 $\mathrm{CuI}^{[74]}$ 等具有较好的稳定性和较低的成本, 已经 在薄膜基钙钛矿 SC 中得到应用, 但是在 PQDs SC 中却鲜有报道。因此急需寻找更加匹配的 HTM, 也 可通过对 HTM 和 PQDs 之间的表界面进行修饰, 或 者构造梯度能级等方法来改善空穴的输运和提取。

虽然上述大量方案能够有效提升 PQDs 基的电 池性能, 为高性能光伏器件的设计和开发提供参考, 但其 PCE 仍需进一步改进, 也可以从薄膜基钙钛矿 和镉基量子点 $\mathrm{SC}$ 领域汲取经验, 在保留 PQDs 优越 光电特性的同时实现更高的 PCE。

\section{3 钙钛矿量子点在荧光聚光电池中的 应用}

LSC 是一种能够将大面积的太阳光转化为高量 子效率的荧光并实现边缘光汇聚的光学器件, 因其 改善太阳能收集能力的潜力而备受关注 ${ }^{[75]}$ 。相比于 传统的聚焦型和反射型聚光技术, LSC 聚光技术不 仅可以吸收散射光, 而且不受太阳光入射角度的影 响, 因此无需配置太阳跟踪装置, 成本更低。同时, LSC 还具有高效率、可柔性化和半透明化等特点, 可直接作为透明窗户使用, 也可安装于屋顶、外墙 等各种建筑表面作为大面积太阳光的收集器, 在聚 光光伏领域具有巨大应用潜力。

将 SC 安装在 LSC 的装置边缘, 本质上形成了 聚光电池, 这里我们称之为荧光型聚光电池, 其工
作原理如图 5(a)所示 ${ }^{[76]}$, 即入射的太阳光被 LSC 中 的高发射苂光材料(如染料、聚合物或量子点)所吸 收, 该材料受激发后以长波长的形式重新发射, 发 射出的光子通过光波导材料并利用全反射原理进行 传播, 从而使得发射光传导至装置的边缘, 并被安 装在边缘处的 SC 吸收。聚光设备可以提高单位面 积 SC 的 PCE, 在相同电能输出情况下, 所需 SC 面 积更小。当 LSC 的聚光效率足够高时, 可以大幅度 降低光伏发电的总成本。具有高发射效率的 PQDs 近年来已被应用于 LSC, 成为光伏能源领域的研究 热点。将该 LSC 结合 SC(通常为硅电池)即可形成苂 光聚光电池, 但文献中并没有对 LSC 与聚光电池进 行细分, 直接将其称为 LSC 进行研究。

实现高效 PQDs 苂光聚光电池的关键在于提升 LSC 的聚光性能, LSC 的性能由外部光学效率来量 化, 有两种测量方法: 一种是直接在 LSC 的一个边 缘耦合功率计来测量, 另一种是在一个边缘耦合标 准 $\mathrm{SC}$ 测量其 $\mathrm{PCE}^{[10]}$, 后者实际为聚光电池的效率, 但人们仍然习惯将其称为 LSC 的外部光学效率。

Shu 等 ${ }^{[77]}$ 采用蒙特卡罗模拟方法追踪了光子从 被发射到全无机 PQDs LSC 原型器件, 再传播到侧 面电池进而被收集的过程, 并预估了该苂光聚光电 池高的外部光学效率, 为 PQDs 在大规模、高性能 LSC 应用的研究提供了一定理论基础, 表明 PQDs 是 一种极具前途的 LSC 吸收/发射材料, 并应用于聚光 电池。实验上, Zhao 等 ${ }^{[78]}$ 将胶体 $\mathrm{CsPb}\left(\mathrm{Br}_{x} \mathrm{I}_{1-x}\right)_{3}$ 量子 点分散于聚合物基质中，可实现吸收波长范围 300 $650 \mathrm{~nm}$ 的半透明复合材料, 通过调节 $\mathrm{Br} / \mathrm{I}$ 比例, 可 以有效增加 PQDs 的 Stokes 位移, 使得吸收和发射 光谱更好地分离, 进而得到具有较宽吸收和较低再 吸收损耗的大面积 LSC 原型器件, 一侧与硅 SC 耦 合后其外部光学效率达到 $2 \%$, 此时几何增益因子(指 LSC 的上表面积与边缘粘贴 SC 面积的比值, 简称 G 因子)高达 45 。通过调节钙钛矿组分, 例如使用少铅 $\mathrm{Cs}\left(\mathrm{Pb}_{y} \mathrm{Sn}_{1-y}\right)\left(\mathrm{Br}_{x} \mathrm{I}_{1-x}\right)_{3}$ 量子点或无铅 $\mathrm{CsSn}\left(\mathrm{Br}_{x} \mathrm{I}_{1-x}\right)_{3}$, 该策略也可应用于近红外 LSC 器件。此后, 该团队 进一步将具有大 Stokes 位移的碳点与 PQDs 结合构 筑了更大面积 $\left(100 \mathrm{~cm}^{2}\right)$ 的串联 LSC 器件, 进一步 将耦合后的聚光器件外部光学效率提升至 3.05\% $\left(100 \mathrm{~mW} \cdot \mathrm{cm}^{-2}\right)$, 比纯 $\mathrm{CsPb}\left(\mathrm{Br}_{x} \mathrm{I}_{1-x}\right)_{3}$ 和 $\mathrm{CsPb}\left(\mathrm{Br}_{x} \mathrm{Cl}_{1-x}\right)_{3}$ 量子点的单层器件分别提高 $27 \%$ 和 $117 \%$ 。

除此之外，稀土离子掺杂 PQDs 可以进一步提高 LSC 的光学转换效率。如将 $\mathrm{Yb}^{3+}$ 引入全无机 PQDs 中可实现几乎为零的自吸收荧光光子损失(图 5(b)), 进而定义了 LSC 的内部光学效率 $150 \%$ 的新上限, 且该值几乎与 $\mathrm{LSC}$ 尺寸无关，实现了 $(118.1 \pm 6.7) \%$ 

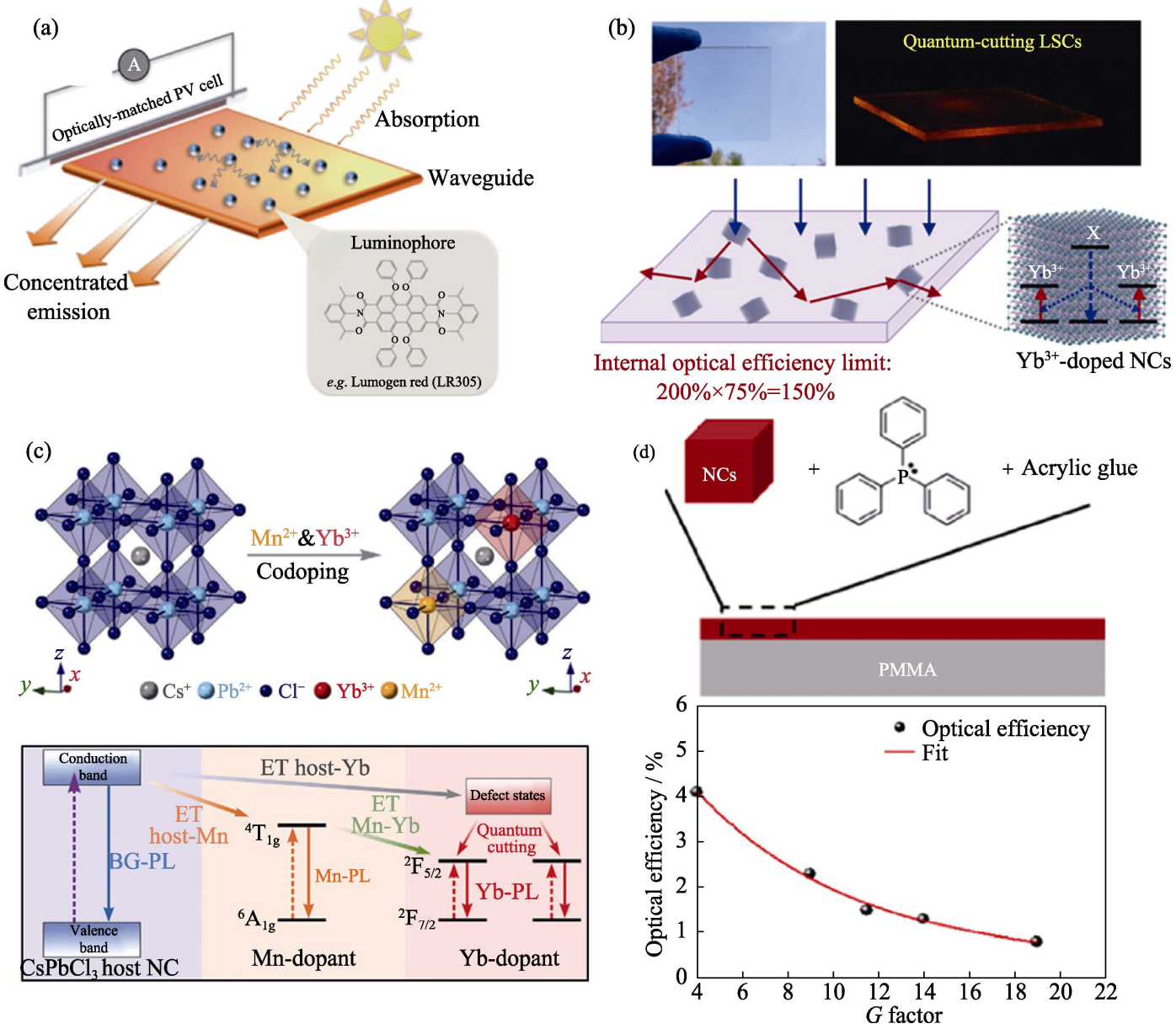

(d)

图 5 (a)苂光聚光电池的工作原理 ${ }^{[76]}$; (b) $\mathrm{Yb}^{3+}$ 掺杂 PQDs 苂光太阳能聚光器在太阳光和紫外灯辐射下的照片及其 光转换示意图 ${ }^{[8]} ;(\mathrm{c}) \mathrm{Mn}^{2+} / \mathrm{Yb}^{3+}$ 共掺杂 $\mathrm{CsPbCl}_{3}$ 量子点的原理图和能量转移过程 ${ }^{[9]}$; (d) 上图: 三苯基膦处理策略

的近红外 LSC, 下图: LSC 与硅太阳能电池耦合后的荧光聚光电池的光学效率与 G 因子的关系曲线 ${ }^{[82]}$

Fig. 5 (a) Operating principle of a luminescent concentrator cell ${ }^{[76]}$; (b) Photos of $\mathrm{Yb}^{3+}$ doped PQDs luminescent solar concentrator (LSC) under sunlight and ultraviolet radiation and its light conversion diagram ${ }^{[8]}$; (c) Schematic illustration and energy transfer (ET) process of $\mathrm{Mn}^{2+} / \mathrm{Yb}^{3+}$ co-doped $\mathrm{CsPbCl}_{3}$ quantum dots ${ }^{[9]}$; (d) Top: near-infrared LSC using triphenylphosphine treatment strategy,

below: optical efficiency of the luminescent concentrator cell coupled with LSC and silicon cell as a function of G-factor ${ }^{[82]}$

的内部光学效率, 是使用金属 $\mathrm{Mn}^{2+}$ 掺杂 PQDs 器件 的 2 倍，同时预估了该策略实现高效率大尺寸 LSC 的可能 ${ }^{[8]}$ 。此后, Cohen 等 ${ }^{[80}$ 基于 $\mathrm{CuInS}_{2}$ 纳米晶的 LSC 与 $\mathrm{Yb}^{3+}$ 掺杂 $\mathrm{CsPb}\left(\mathrm{Cl}_{1-x} \mathrm{Br}_{x}\right)_{3}$ 量子点集成, 利用 该 PQDs 的上述优势, 预测集成的聚光器件性能至 少提高 $19 \%$ 。 $\mathrm{Cai}$ 等 ${ }^{[9]}$ 验证了 $\mathrm{Yb}^{3+}$ 掺杂对材料再吸 收损失的削弱效应，同时利用 $\mathrm{Mn}^{2+} / \mathrm{Yb}^{3+}$ 量子点共 掺策略, 由于 PQDs 主体材料向掺杂离子以及 $\mathrm{Mn}^{2+}$ 向 $\mathrm{Yb}^{3+}$ 的能量转移过程，展现出三波长发射特性 (图 5(c))。实验和模拟结果显示, $G$ 因子为 3.0 时, 共 掺杂 $\mathrm{LSC}$ 的外部光学效率从 $3.1 \%\left(\mathrm{Mn}^{2+}\right.$ 掺杂 $\left.\mathrm{LSC}\right)$ 大幅提升至 $9.6 \%$, 提高了 2.1 倍，与硅太阳能电池 结合形成的聚光电池效率也得到了一定改善。

配体处理策略也是提高 PQDs 基 LSC 性能的手 段之一。如二羧酸配体相比于传统的油酸配体钝化 的 $\mathrm{FAPbBr}_{3}$ 量子点具有更高的苂光量子产率和稳定 性。进一步与聚苯乙烯(PS)/甲苯结合可形成具有适
当黏度的浆液，该浆液极易刮涂，可沉积在聚甲基 丙烯酸甲酯板上，形成高苂光量子产率(92\%)、耐高 温和抗高湿度的复合材料板，该材料可进一步推广 至 $\mathrm{LSC}$ 领域 ${ }^{[81]}$ 。Wu 等 ${ }^{[82]}$ 采用三苯基膦配体处理的 方法, 实现了高发光效率、低重吸收和高稳定性的 大面积 $\left(75 \mathrm{~cm}^{2}\right)$ 近红外 $\mathrm{CsPbI}_{3}$ 量子点 $\mathrm{LSC}$ 原型器件, 在 $\mathrm{G}$ 因子为 10 时, 得到的苂光聚光电池的外部光学 效率可达 3.1\%(图 5(d))。

LSC 作为一种聚光器, 是聚光电池研究的关键 技术之一，其目的是收集分散的太阳光，增强较小 面积上的太阳光光能密度, 对提高太阳能电池的 PCE 和降低电池应用的总成本具有重大意义。目前, 聚光电池主要采用的是 GaAs 等 III-V 族化合物多结 电池或硅单结电池，价格昂贵且工艺复杂，且所使 用的聚光系统由于对入射光角度的依赖性常需配备 太阳跟踪装置，还存在散热等问题。而 PQDs 除了 具有高荧光量子产率和宽吸收等光学特性, 还以合 
成工艺简单和低成本著称, 有望在太阳能电池和苂 光聚光电池领域有所作为, 在获得高光电转换效率 的同时极大降低应用成本。而基于 PQDs 的 LSC 的 研究尚处于起步阶段, 其聚光电池的效率甚至低于 原始电池, 仍待进一步改善, 高效率 LSC 将推动 PQDs 开展在苂光聚光电池领域的后续工作。

\section{4 总结与展望}

卤化物钙钛矿量子点凭借优异的光电特性在太 阳能电池和荧光聚光电池领域均展现出广阔的应用 前景, 但是仍然存在诸多挑战。例如相较于薄膜基钙 钛矿太阳能电池, 钙钛矿量子点太阳能电池的光电 转换效率仍然较低; 其在荧光聚光电池中的开发尚 存在较大提升空间, 关键在于提升聚光设备效率, 同时高效率太阳能电池将有望替代该聚光电池中昂 贵的硅太阳能电池。此外, 钙钛矿材料的稳定性以及 铅的毒性也是钙钛矿光电子器件领域难以回避的挑 战, 仍然缺乏详细且系统的器件工作机理内涵研究; 同时光电子器件面向未来实际应用, 实现大面积制 造及柔性化也是发展潮流。针对上述问题, 并结合材 料的自身特性及上述研究进展, 作者对该类型材料 在太阳能电池和荧光聚光电池领域的后续研究趋势 作出如下展望。

1) 钻钛矿组分调控及无铅化: 适当的组分调控 (离子替换或掺杂)除了改善 PQDs 的光电特性之外, 还有助于提高材料的结构稳定性。单一元素的使用 往往引入某一缺陷, 因此可采用两种甚至多种元素 共同作用, 最大程度优化材料性能。此外, 使用无毒 金属元素取代铅是未来应用的必选要求, 目前常用 的金属元素有 $\mathrm{Sn}$ 和 $\mathrm{Ge}$ 等, 但是其结构稳定性远不如 铅基钙钛矿, 因此探索稳定的无铅钙钛矿体系, 如 新型的双 PQDs 也是未来的研究方向, 有助于解决铅 毒性危害的问题。

2) 材料和器件的表界面修饰: PQDs 表面配体的 高度动态化使之容易丢失配体导致大量表面缺陷, 进而增加载流子在缺陷位点处被捕获的概率, 因此 可使用结合能力强同时导电性良好的表面配体对其 表面进行有效钝化。而多层结构的太阳能电池具有 多个界面, 各功能层之间的界面缺陷也会捕获光生 载流子, 同时太阳能电池的能级不匹配将导致电子 和空穴无法高效分离。因此, 可选用合适的界面修饰 材料, 优化功能层形貌、促进载流子输运、降低缺陷 密度或修饰能级, 以达到提升器件性能的目的。

3) 串联结构助稳增效: 构筑由多个不同带隙组 成的串联结构 SC 可增加对太阳光谱的有效利用率,
是突破单结电池 Shockley-Queisser 效率极限的一种 最重要方法。溶液法制备的 PQDs SC 极易与其他类 型的 SC 通过隧穿复合结连接形成虫联结构, 如硅、 钙钛矿、染料敏化、有机和量子点 $\mathrm{SC}$ 等。因此可通 过设计与 PQDs SC 高度匹配的串联叠层结构 SC 来 进一步提高器件效率, 这里除了要考虑子电池自身 特性，隧穿复合结还应该具有良好的致密性、高的透 光性和低的串联电阻。而 PQDs SC 与高稳定性的电 池结合时, 还能够弥补钙钠矿 $\mathrm{SC}$ 稳定性差的缺陷。

4) 器件机理探索: 除了性能参数改进策略, 应 结合理论模拟和原位表征手段, 对器件内部的工作 机理进行深入探索, 研究器件内部光生载流子的产 生、分离、输运及复合机制等微观动力学行为, 分析 器件内建电场对载流子输运和分离的影响。同时, 需 要重视器件多个功能层间的界面效应, 研究界面材 料对载流子输运、缺陷捕获、离子迁移等影响的规 律。更为重要的是, 通过大量理论和实验数据分析, 建立一套完整的工作理论体系, 这将为后续实验工 作提供有针对性的开发设计思路, 能极大地缩短研 究进程。

5) 大面积制造及柔性化: 针对 PQDs 在光伏技 术中的应用大多局限于小面积和真空环境, 尚未实 现大规模工业化生产。柔性器件在可穿戴电子设备、 便携式充电设备以及各种物体或建筑表面等应用领 域均可涉猎。在未来研究中, 大规模制备、柔性器件 以及设备产业化才是未来发展的最终目标。而 PQDs 多样化的溶液加工能力使之能够适用于构建各种大 面积、柔性太阳能电池和聚光电池。因此抛开大多 原型器件使用的旋涂或滴涂制膜工艺, 面向未来应 用, PQDs 仍需要开发成本更低且适用于大规模制造 流程(如刮涂、喷墨印刷等)的墨水配方。

\section{参考文献:}

[1] LEIJTENS T, STRANKS S D, EPERON G E, et al. Electronic properties of meso-superstructured and planar organometal halide perovskite films: charge trapping, photodoping, and carrier mobility. ACS Nano, 2014, 8(7): 7147-7155.

[2] FU P, SHAN Q, SHANG Y, et al. Perovskite nanocrystals: synthesis, properties and applications. Science Bulletin, 2017, 62(5): 369-380.

[3] XING G, MATHEWS N, SUN S, et al. Long-range balanced electronand hole-transport lengths in organic-inorganic $\mathrm{CH}_{3} \mathrm{NH}_{3} \mathrm{PbI}_{3}$. Science, 2013, 342(6156): 344-347.

[4] DONG Q, FANG Y, SHAO Y, et al. Electron-hole diffusion lengths $>175 \mathrm{~mm}$ in solution-grown $\mathrm{CH}_{3} \mathrm{NH}_{3} \mathrm{PbI}_{3}$ single crystals. Science, 2015, 347(6225): 967-970.

[5] DE WOLF S, HOLOVSKY J, MOON S J, et al. Organometallic halide perovskites: sharp optical absorption edge and its relation to photovoltaic performance. Journal of Physical Chemistry Letters, 2014, 5(6): 1035-1039. 
[6] PARK N G. Perovskite solar cells: an emerging photovoltaic technology. Materials Today, 2015, 18(2): 65-72.

[7] JEONG J, KIM M, SEO J, et al. Pseudo-halide anion engineering for alpha-FAPbI ${ }_{3}$ perovskite solar cells. Nature, 2021, 592(7854): 381-385.

[8] LUO X, DING T, LIU X, et al. Quantum-cutting luminescent solar concentrators using ytterbium-doped perovskite nanocrystals. Nano Letters, 2019, 19(1): 338-341.

[9] CAI T, WANG J, LI W, et al. $\mathrm{Mn}^{2+} / \mathrm{Yb}^{3+}$ codoped $\mathrm{CsPbCl}_{3}$ perovskite nanocrystals with triple-wavelength emission for luminescent solar concentrators. Advanced Science, 2020, 7(18): 2001317.

[10] ZHAO H, SUN R, WANG Z, et al. Zero-dimensional perovskite nanocrystals for efficient luminescent solar concentrators. Advanced Functional Materials, 2019, 29(30): 1902262.

[11] YOO J J, SEO G, CHUA M R, et al. Efficient perovskite solar cells via improved carrier management. Nature, 2021, 590(7847): 587-593.

[12] ZHAO Q, HAZARIKA A, CHEN X, et al. High efficiency perovskite quantum dot solar cells with charge separating heterostructure. Nature Communications, 2019, 10(1): 2842.

[13] HAO M, BAI Y, ZEISKE S, et al. Ligand-assisted cation-exchange engineering for high-efficiency colloidal $\mathrm{Cs}_{1-x} \mathrm{FA}_{x} \mathrm{PbI}_{3}$ quantum dot solar cells with reduced phase segregation. Nature Energy, 2020, 5(1): 79-88.

[14] KOJIMA A, TESHIMA K, SHIRAI Y, et al. Organometal halide perovskites as visible-light sensitizers for photovoltaic cells. Journal of the American Chemical Society, 2009, 131(17): 6050-6051.

[15] IM J H, LEE C R, LEE J W, et al. 6.5\% efficient perovskite quantumdot-sensitized solar cell. Nanoscale, 2011, 3(10): 4088-4093.

[16] KIM H S, LEE C R, IM J H, et al. Lead iodide perovskite sensitized all-solid-state submicron thin film mesoscopic solar cell with efficiency exceeding 9\%. Scientific Reports, 2012, 2: 591.

[17] LEE M M, TEUSCHER J, MIYASAKA T, et al. Efficient hybrid solar cells based on meso-superstructured organometal halide perovskites. Science, 2012, 338(6107): 643-647.

[18] LEI Y, GU L, HE W, et al. Intrinsic charge carrier dynamics and device stability of perovskite/ZnO mesostructured solar cells in moisture. Journal of Materials Chemistry A, 2016, 4(15): 5474-5481.

[19] BALL J M, LEE M M, HEY A, et al. Low-temperature processed meso-superstructured to thin-film perovskite solar cells. Energy \& Environmental Science, 2013, 6(6): 1739-1743.

[20] BI D, MOON S J, HÄGGMAN L, et al. Using a two-step deposition technique to prepare perovskite $\left(\mathrm{CH}_{3} \mathrm{NH}_{3} \mathrm{PbI}_{3}\right)$ for thin film solar cells based on $\mathrm{ZrO}_{2}$ and $\mathrm{TiO}_{2}$ mesostructures. RSC Advances, 2013, 3(41): 18762-18766.

[21] ZHOU F, LI Z, CHEN H, et al. Application of perovskite nanocrystals (NCs)/quantum dots (QDs) in solar cells. Nano Energy, 2020, 73: 104757.

[22] MENG L, YOU J, GUO T F, et al. Recent advances in the inverted planar structure of perovskite solar cells. Accounts of Chemical Research, 2016, 49(1): 155-165.

[23] MARCHIORO A, TEUSCHER J, FRIEDRICH D, et al. Unravelling the mechanism of photoinduced charge transfer processes in lead iodide perovskite solar cells. Nature Photonics, 2014, 8(3): 250-255.

[24] LINABURG M R, MCCLURE E T, MAJHER J D, et al. $\mathrm{Cs}_{1-x} \mathrm{Rb}_{x} \mathrm{PbCl}_{3}$ and $\mathrm{Cs}_{1-x} \mathrm{Rb}_{x} \mathrm{PbBr}_{3}$ solid solutions: understanding octahedral tilting in lead halide perovskites. Chemistry of Materials, 2017, 29(8): 3507-3514.

[25] CHO H, KIM Y H, WOLF C, et al. Improving the stability of metal halide perovskite materials and light-emitting diodes. Advanced Materials, 2018, 30(42): 1704587.

[26] HAZARIKA A, ZHAO Q, GAULDING E A, et al. Perovskite quantum dot photovoltaic materials beyond the reach of thin films: full-range tuning of A-site cation composition. ACS Nano, 2018,
12(10): 10327-10337.

[27] SMITH I C, HOKE E T, SOLIS-IBARRA D, et al. A layered hybrid perovskite solar-cell absorber with enhanced moisture stability. Angewandte Chemie International Edition, 2014, 53(42): 11232-11235.

[28] ZHOU N, SHEN Y, LI L, et al. Exploration of crystallization kinetics in quasi two-dimensional perovskite and high performance solar cells. Journal of the American Chemical Society, 2018, 140(1): 459-465.

[29] XUE J, LEE J W, DAI Z, et al. Surface ligand management for stable $\mathrm{FAPbI}_{3}$ perovskite quantum dot solar Cells. Joule, 2018, 2(9): 1866-1878.

[30] JI K, YUAN J, LI F, et al. High-efficiency perovskite quantum dot solar cells benefiting from a conjugated polymer-quantum dot bulk heterojunction connecting layer. Journal of Materials Chemistry A, 2020, 8(16): 8104-8112.

[31] SHEN X, ZHANG Y, KERSHAW S V, et al. Zn-alloyed $\mathrm{CsPbI}_{3}$ nanocrystals for highly efficient perovskite light-emitting devices. Nano Letters, 2019, 19(3): 1552-1559.

[32] JIANG Y, YUAN J, NI Y, et al. Reduced-dimensional $\alpha$-CsPbX perovskites for efficient and stable photovoltaics. Joule, 2018, 2(7): 1356-1368.

[33] CHEN J, JIA D, JOHANSSON E M J, et al. Emerging perovskite quantum dot solar cells: feasible approaches to boost performance. Energy \& Environmental Science, 2021, 14(1): 224-261.

[34] JEON N J, NOH J H, YANG W S, et al. Compositional engineering of perovskite materials for high-performance solar cells. Nature, 2015, 517(7535): 476-480.

[35] WANG C, ZHAO D, YU Y, et al. Compositional and morphological engineering of mixed cation perovskite films for highly efficient planar and flexible solar cells with reduced hysteresis. Nano Energy, 2017, 35: 223-232.

[36] YE J, BYRANVAND M M, MARTINEZ C O, et al. Defect passivation in lead-halide perovskite nanocrystals and thin films: toward efficient LEDs and solar cells. Angewandte Chemie International Edition, 2021, 60(40): 21636-21660.

[37] AKKERMAN Q A, RAINO G, KOVALENKO M V, et al. Genesis, challenges and opportunities for colloidal lead halide perovskite nanocrystals. Nature Materials, 2018, 17(5): 394-405.

[38] KUMAWAT N K, GUPTA D, KABRA D. Recent advances in metal halide-based perovskite light-emitting diodes. Energy Technology, 2017, 5(10): 1734-1749.

[39] CHEN Q, DE MARCO N, YANG Y, et al. Under the spotlight: the organic-inorganic hybrid halide perovskite for optoelectronic applications. Nano Today, 2015, 10(3): 355-396.

[40] AZPIROZ J M, MOSCONI E, BISQUERT J, et al. Defect migration in methylammonium lead iodide and its role in perovskite solar cell operation. Energy \& Environmental Science, 2015, 8(7): 2118-2127.

[41] SWARNKAR A, MIR W J, NAG A. Can B-site doping or alloying improve thermal- and phase-stability of all-inorganic $\mathrm{CsPbX}_{3}(\mathrm{X}=$ Cl, Br, I) perovskites? ACS Energy Letters, 2018, 3(2): 286-289.

[42] WANG Y, TU J, LI T, et al. Convenient preparation of $\mathrm{CsSnI}_{3}$ quantum dots, excellent stability, and the highest performance of leadfree inorganic perovskite solar cells so far. Journal of Materials Chemistry A, 2019, 7(13): 7683-7690.

[43] LIU M, PASANEN H, ALI-LOYTTY H, et al. B-site co-alloying with germanium improves the efficiency and stability of all-inorganic tin-based perovskite nanocrystal solar cells. Angewandte Chemie International Edition, 2020, 59(49): 22117-22125.

[44] AHMAD R, NUTAN G V, SINGH D, et al. Colloidal lead-free $\mathrm{Cs}_{2} \mathrm{AgBiBr}_{6}$ double perovskite nanocrystals: synthesis, uniform thin-film fabrication, and application in solution-processed solar cells. Nano Research, 2020, 14(4): 1126-1134.

[45] ZHANG J, JIN Z, LIANG L, et al. Iodine-optimized interface for inorganic $\mathrm{CsPbI}_{2} \mathrm{Br}$ perovskite solar cell to attain high stabilized 
efficiency exceeding 14\%. Advanced Science, 2018, 5(12): 1801123.

[46] CHEN K, ZHONG Q, CHEN W, et al. Short-chain ligand-passivated stable $\alpha-\mathrm{CsPb}_{3}$ quantum dot for all-inorganic perovskite solar cells. Advanced Functional Materials, 2019, 29(24): 1900991.

[47] BIAN H, BAI D, JIN Z, et al. Graded bandgap $\mathrm{CsPbI}_{2+x} \mathrm{Br}_{1-x}$ perovskite solar cells with a stabilized efficiency of 14.4\%. Joule, 2018, 2(8): $1500-1510$

[48] YUAN J, BI C, WANG S, et al. Spray-coated colloidal perovskite quantum dot films for highly efficient solar cells. Advanced Functional Materials, 2019, 29(49): 1906615.

[49] LIU C, ZENG Q, ZHAO Y, et al. Surface ligands management for efficient $\mathrm{CsPbBrI}_{2}$ perovskite nanocrystal solar cells. Solar $R R L$, 2020, 4(5): 2000102

[50] LI J, XU L, WANG T, et al. 50-fold EQE improvement up to $6.27 \%$ of solution-processed all-inorganic perovskite $\mathrm{CsPbBr}_{3}$ QLEDs via surface ligand density control. Advanced Materials, 2017, 29(5): 1603885.

[51] CHIBA T, HOSHI K, PU Y J, et al. High-efficiency perovskite quantum-dot light-emitting devices by effective washing process and interfacial energy level alignment. ACS Applied Materials \& Interfaces, 2017, 9(21): 18054-18060.

[52] JIA D, CHEN J, YU M, et al. Dual passivation of $\mathrm{CsPb}_{3}$ perovskite nanocrystals with amino acid ligands for efficient quantum dot solar cells. Small, 2020, 16(24): 2001772.

[53] WHEELER L M, SANEHIRA E M, MARSHALL A R, et al. Targeted ligand-exchange chemistry on cesium lead halide perovskite quantum dots for high-efficiency photovoltaics. Journal of the American Chemical Society, 2018, 140(33): 10504-10513.

[54] KIM J, CHO S, DINIC F, et al. Hydrophobic stabilizer-anchored fully inorganic perovskite quantum dots enhance moisture resistance and photovoltaic performance. Nano Energy, 2020, 75: 104985.

[55] SANEHIRA E M, MARSHALL A R, CHRISTIANS J A, et al. Enhanced mobility $\mathrm{CsPbI}_{3}$ quantum dot arrays for record-efficiency, high-voltage photovoltaic cells. Science Advances, 2017, 3(10): eaao4204.

[56] LING X, ZHOU S, YUAN J, et al. $14.1 \% \mathrm{CsPbI}_{3}$ perovskite quantum dot solar cells via cesium cation passivation. Advanced Energy Materials, 2019, 9(28): 1900721.

[57] LING X, YUAN J, ZHANG X, et al. Guanidinium-assisted surface matrix engineering for highly efficient perovskite quantum dot photovoltaics. Advanced Materials, 2020, 32(26): 2001906.

[58] LI F, ZHOU S, YUAN J, et al. Perovskite quantum dot solar cells with $15.6 \%$ efficiency and improved stability enabled by an $\alpha-\mathrm{CsPI}_{3} /$ $\mathrm{FAPbI}_{3}$ bilayer structure. ACS Energy Letters, 2019, 4(11): 2571-2578.

[59] PARK S Y, SHIM H C. Highly efficient and air-stable heterostructured perovskite quantum dot solar cells using a solid-state cationexchange reaction. ACS Applied Materials \& Interfaces, 2020, 12(51): 57124-57133.

[60] XUE J, WANG R, CHEN L, et al. A small-molecule "charge driver" enables perovskite quantum dot solar cells with efficiency approaching 13\%. Advanced Materials, 2019, 31(37): 1900111.

[61] GAULDING E A, HAO J, KANG H S, et al. Conductivity tuning via doping with electron donating and withdrawing molecules in perovskite $\mathrm{CsPbI}_{3}$ nanocrystal films. Advanced Materials, 2019, 31(27): 1902250

[62] WANG S, BI C, PORTNIAGIN A, et al. $\mathrm{CsPbI}_{3} / \mathrm{PbSe}$ heterostructured nanocrystals for high-efficiency solar cells. ACS Energy Letters, 2020, 5(7): 2401-2410.

[63] DING C, LIU F, ZHANG Y, et al. Photoexcited hot and cold electron and hole dynamics at $\mathrm{FAPbI}_{3}$ perovskite quantum dots/metal oxide heterojunctions used for stable perovskite quantum dot solar cells. Nano Energy, 2020, 67: 104267.

[64] WANG Q, JIN Z, CHEN D, et al. $\mu$-Graphene crosslinked $\mathrm{CsPbI}_{3}$ quantum dots for high efficiency solar cells with much improved stability. Advanced Energy Materials, 2018, 8(22): 1800007.

[65] CHEN K, JIN W, ZHANG Y, et al. High efficiency mesoscopic solar cells using $\mathrm{CsPbI}_{3}$ perovskite quantum dots enabled by chemical interface engineering. Journal of the American Chemical Society, 2020, 142(8): 3775-3783.

[66] XIONG L, GUO Y, WEN J, et al. Review on the application of $\mathrm{SnO}_{2}$ in perovskite solar cells. Advanced Functional Materials, 2018, 28(35): 1802757.

[67] JIANG Q, ZHANG L, WANG H, et al. Enhanced electron extraction using $\mathrm{SnO}_{2}$ for high-efficiency planar-structure $\mathrm{HC}\left(\mathrm{NH}_{2}\right)_{2} \mathrm{PbI}_{3}$ based perovskite solar cells. Nature Energy, 2016, 2(1): 16177.

[68] LIM S, KIM J, PARK J Y, et al. Suppressed degradation and enhanced performance of $\mathrm{CsPbI}_{3}$ perovskite quantum dot solar cells via engineering of electron transport layers. ACS Applied Materials \& Interfaces, 2021, 13(5): 6119-6129.

[69] SHIVARUDRAIAH S B, NG M, LI C H A, et al. All-inorganic, solution-processed, inverted $\mathrm{CsPbI}_{3}$ quantum dot solar cells with a PCE of $13.1 \%$ achieved via a layer-by-layer FAI treatment. ACS Applied Energy Materials, 2020, 3(6): 5620-5627.

[70] DING X, CAI M, LIU X, et al. Lead sulfide quantum dots as a bifunctional layer for efficient and stable all-inorganic cesium lead iodide perovskite solar cells. ChemistrySelect, 2019, 4(45): 13143-13148

[71] ZENG Q, ZHANG X, FENG X, et al. Polymer-passivated inorganic cesium lead mixed-halide perovskites for stable and efficient solar cells with high open-circuit voltage over 1.3 V. Advanced Materials, 2018, 30(9): 1705393.

[72] YUAN J, LING X, YANG D, et al. Band-aligned polymeric hole transport materials for extremely low energy loss $\alpha-\mathrm{CsPbI}_{3}$ perovskite nanocrystal solar cells. Joule, 2018, 2(11): 2450-2463.

[73] ARORA N, DAR M I, HINDERHOFER A, et al. Perovskite solar cells with $\mathrm{CuSCN}$ hole extraction layers yield stabilized efficiencies greater than 20\%. Science, 2017, 358(6364): 768-771.

[74] CHRISTIANS J A, FUNG R C, KAMAT P V. An inorganic hole conductor for organo-lead halide perovskite solar cells. Improved hole conductivity with copper iodide. Journal of the American Chemical Society, 2014, 136(2): 758-764.

[75] LIU G, MAZZARO R, WANG Y, et al. High efficiency sandwich structure luminescent solar concentrators based on colloidal quantum dots. Nano Energy, 2019, 60: 119-126.

[76] MCKENNA B, EVANS R C. Towards efficient spectral converters through materials design for luminescent solar devices. Advanced Materials, 2017, 29(28): 1606491.

[77] SHU J, ZHANG X, WANG P, et al. Monte-Carlo simulations of optical efficiency in luminescent solar concentrators based on allinorganic perovskite quantum dots. Physica B: Condensed Matter, 2018, 548: 53-57.

[78] ZHAO H, ZHOU Y, BENETTI D, et al. Perovskite quantum dots integrated in large-area luminescent solar concentrators. Nano Energy, 2017, 37: 214-223.

[79] ZHAO H, BENETTI D, TONG X, et al. Efficient and stable tandem luminescent solar concentrators based on carbon dots and perovskite quantum dots. Nano Energy, 2018, 50: 756-765.

[80] COHEN T A, MILSTEIN T J, KROUPA D M, et al. Quantumcutting $\mathrm{Yb}^{3+}$-doped perovskite nanocrystals for monolithic bilayer luminescent solar concentrators. Journal of Materials Chemistry A, 2019, 7(15): 9279-9288.

[81] TONG J, LUO J, SHI L, et al. Fabrication of highly emissive and highly stable perovskite nanocrystal-polymer slabs for luminescent solar concentrators. Journal of Materials Chemistry A, 2019, 7(9): 4872-4880.

[82] WU J, TONG J, GAO Y, et al. Efficient and stable thin-film luminescent solar concentrators enabled by near-infrared emission perovskite nanocrystals. Angewandte Chemie International Edition, 2020, 132(20): 7812-7816. 